Revista Destaques Acadêmicos, Lajeado, v. 8, n. 3, 2016. ISSN 2176-3070 DOI: http://dx.doi.org/10.22410/issn.2176-3070.v8i3a2016.1183 www.univates.br/revistas

\title{
O UNIVERSO DOS BOLSISTAS
}

\author{
Júlia Andressa Portz ${ }^{1}$, Márcia Werner²
}

Resumo: $O$ presente artigo tem como principal objetivo compreender as práticas de bolsistas por meio do relato de uma intervenção realizada no estágio curricular básico de psicologia. A intervenção foi de cunho qualitativo, descritivo e a coleta de dados ocorreu por meio de entrevistas semiestruturadas, realizadas com professores e funcionário técnico-administrativo, e de grupos focais, com bolsistas de extensão e de pesquisa. A análise dos dados foi elaborada com base na Análise de Conteúdo. Conclui-se que não existe um modo único de ser bolsista, o qual pode ser percebido como importante momento da aprendizagem do acadêmico e constitui-se em base fundamental no processo de trabalho que envolve a bolsa científica e auxilia na construção da carreira acadêmica. Os desafios que os bolsistas enfrentam são diversos, mas a realização do estágio e seus benefícios são fundamentais para o crescimento e amadurecimento profissional.

Palavras-chave: Estágio. Psicologia. Bolsistas.

\section{INTRODUÇÃO}

A realização do estágio curricular básico do curso de psicologia no setor de Recursos Humanos (RH) de uma Instituição de Ensino Superior (IES) aproximou-me ${ }^{3}$ da realidade dos bolsistas que atuam nessa instituição. A IES desenvolve trabalhos específicos voltados aos professores, funcionários técnico-administrativos, aos trabalhadores terceirizados, estagiários e, mais recentemente, tem buscado uma aproximação com os bolsistas.

Como proposta de intervenção durante o estágio busquei conhecer os bolsistas e as atividades que esse grupo específico realiza. Esse processo foi um desafio, com alguns impasses e boas surpresas. Fazer análise da produção de

1 Graduada em Psicologia pelo Centro Universitário UNIVATES (2015).

2 Personal \& Professional Coach pela SBC (2013). Especialista em Violência pela USP-SP (2004). Mestre em Psicologia pela UFRGS (2002) e graduada em Psicologia pela UNISINOS (1999).

3 O presente artigo trata-se de um relato de experiência e, por esse motivo, foi escrito em primeira pessoa. 
uma demanda, segundo Baremblitt (2002), consiste no cuidadoso exame que a organização ou a pessoa faz da maneira como a instituição oferece seus serviços. Para esse autor não existe demanda espontânea. Toda demanda é produzida, é gerada. Ela designa o conjunto de desejos (conscientes e $\backslash$ ou inconscientes), assim como as vontades, interesses, crenças valores e situações que levam os coletivos institucionais a solicitar uma intervenção institucional.

Durante a realização da intervenção fui percebendo quão importante era entender as subjetividades dos bolsistas que na IES exercem suas funções. $\mathrm{Na}$ intervenção institucional, segundo Guirado (2004), coloca-se em destaque a necessidade de se pensar as subjetividades constituídas nas relações institucionais. Os bolsistas possuem características particulares que exigem um olhar diferenciado, o propósito de trabalho deles é diferente dos funcionários e a relação com a IES também.

O presente artigo tem como principal objetivo compreender as práticas dos bolsistas de pesquisa e extensão por meio do relato de experiência realizada no estágio curricular básico de psicologia.

\section{METODOLOGIA}

Foi realizada intervenção de cunho qualitativo, descritivo. Para Goldenberg (2013), os pesquisadores que optam pela abordagem qualitativa não defendem um modelo único de pesquisa. Eles afirmam que as ciências sociais têm suas especificidades, que pressupõem metodologias particulares. Os pesquisadores qualitativos têm interesse nas experiências e interações que ocorrem em seu contexto natural, de uma maneira que propicie espaço às particularidades do que se está pesquisando. A pesquisa qualitativa parte da ideia de que os métodos e a teoria devem ser ajustados àquilo que se estuda. Em outras palavras, ela se dirige à análise de casos concretos em suas particularidades locais e temporais, partindo das expressões e atividades das pessoas em seus contextos locais (FLICK, 2009).

Com a pesquisa qualitativa me aproximei das particularidades locais e temporais do grupo de bolsistas. Pude perceber suas especificidades, o que eles entendem de sua função na IES quais são os desafios, responsabilidades, realizações e as experiências que a bolsa proporciona para esses sujeitos. Flick (2009) considera que os pesquisadores são uma parte importante no processo de pesquisa, seja pela presença pessoal ou pelas experiências no campo e capacidade de reflexão. A subjetividade do pesquisador, bem como daqueles que estão sendo estudados, tornam-se parte do processo da pesquisa.

Da mesma forma, Goldenberg (2013) afirma que é preciso atentar quanto ao papel do pesquisador, uma vez que a pesquisa qualitativa diz respeito à possível contaminação dos seus resultados em função da personalidade do mesmo e de seus valores. O pesquisador afeta as respostas do grupo ou indivíduo que pesquisa. Por isso, a melhor forma de controlar esta interferência 
é tendo consciência de como sua presença interfere no grupo e até que ponto este fato pode ser minimizado ou analisado como dado de pesquisa.

A pesquisa descritiva, por sua vez, tem a finalidade primordial de descrever as características de determinada população ou fenômeno ou a relação entre as variáveis (GIL, 2011). Com a intervenção pude descrever as características singulares dos bolsistas.

No local do estudo, os bolsistas dividem-se em três principais grupos: de Pesquisa, de Extensão e do Programa Institucional de Bolsa de Iniciação à Docência (PIBID). Esse grupo soma, aproximadamente, 148 bolsistas de pesquisa, 42 bolsistas de extensão e 181 bolsistas do PIBID.

Os bolsistas que se envolvem em projetos de pesquisa são vinculados a bolsas de iniciação científica e, por isso, têm o compromisso de apresentar suas produções científicas nos Salões de Iniciação Científica (SIC). Os bolsistas de projetos de extensão realizam um trabalho mais prático, no qual têm a possibilidade de se experimentar fora da sala de aula. Ambos os grupos de bolsistas cumprem carga horária de 30 horas semanais. Os bolsistas do PIBID são alunos da graduação, dos cursos de Licenciatura, que se aproximam da prática de ser professor indo para a escola durante quatro horas semanais e em outras quatro horas elaboram na IES as atividades que serão realizadas na primeira. Este último grupo de bolsistas totaliza oito horas semanais de bolsa. E, por ter características diferentes dos outros dois grupos, eles não foram envolvidos no estudo. Foram incluídos seis sujeitos no estudo, envolvidos com atividades de pesquisa e extensão.

Em relação aos métodos de coleta de dados utilizei duas formas diferentes: entrevistas semiestruturadas e grupos focais. O objetivo de fazer uso desses métodos foi adquirir quantidade maior de informações sobre o universo dos bolsistas, a fim de oferecer à IES relato detalhado da realidade dos mesmos.

Conforme Pinheiro (2004), na Psicologia a entrevista é amplamente utilizada tanto na prática profissional, como em pesquisa. Ela fundamenta diversas abordagens teórico-metodológicas e é considerada como prática discursiva, ou seja, entendida como ação, interação situada e contextualizada, por meio da qual se produzem sentidos e se constroem versões de realidade. Foram realizadas entrevistas semiestruturadas com um funcionário técnicoadministrativo e cinco professores que atuam diretamente com os bolsistas na IES. Cada entrevista teve duração de meia hora.

De acordo com Fraser e Gondim (2004), a entrevista semiestruturada é definida como uma entrevista na qual o entrevistador introduz o tema da pesquisa e permite que o entrevistado discorra livremente sobre o tema, fazendo apenas interferências pontuais. Os autores afirmam que é comum numa entrevista a elaboração de um roteiro apresentado sob a forma de tópicos que oriente a condução da entrevista. As seguintes questões nortearam as entrevistas semiestruturadas: O que é ser bolsista? Qual a importância dos bolsistas para 
a IES? Por quê? Na sua atuação, qual suporte você dá aos bolsistas? Quais as dificuldades que você encontra no trabalho com os bolsistas? Você acredita que seja importante uma maior aproximação para com os bolsistas? Você tem sugestões de melhorias para os bolsistas?

Com as entrevistas, consegui me aproximar do entendimento que o funcionário e professores que atuam com os bolsistas, possuem sobre a realidade dos mesmos, alcançando os objetivos que pretendia com a intervenção. Elas me possibilitaram ter contato com os sentidos e versões que cada um dos entrevistados possui em relação ao contexto dos bolsistas.

Na realização das entrevistas tive alguns impasses que resultaram em entrevistas fora do horário de estágio, novos agendamentos. A ansiedade para realização da primeira entrevista foi algo inevitável, mas no decorrer das atividades fui me sentindo mais tranquila, confiante. De modo geral, as entrevistas ocorreram de forma natural, proveitosa, algumas mais descontraídas, com direito a chimarrão, fazendo com que a minha segurança na prática profissional fosse crescendo.

O método de grupo focal é uma abordagem qualitativa e serve como bom instrumento de levantamento de dados para investigações em ciências humanas e sociais (GATTI, 2005).

O trabalho com grupos focais permite compreender processos de construção da realidade por determinados grupos sociais, compreender práticas cotidianas, ações e reações a fatos e eventos, comportamentos e atitudes, constituindo-se uma técnica importante para o conhecimento das representações, percepções, crenças, hábitos, valores, restrições, preconceitos, linguagens e simbologias prevalentes no trato de uma dada questão por pessoas que partilham alguns traços em comum, relevantes para o estudo do problema visado. A pesquisa com grupos focais, além de ajudar na obtenção de perspectivas diferentes sobre uma mesma questão, permite também a compreensão de ideias partilhadas por pessoas no dia-adia e dos modos pelos quais os indivíduos são influenciados pelos outros (GATTI, 2005, p. 11).

Por meio dos grupos focais, os sujeitos expressaram a realidade dos bolsistas, as práticas que fazem parte do seu cotidiano, os eventos de que participam, seus desafios, ansiedades e realizações. Foram realizados dois grupos focais, um com cinco bolsistas de extensão e o outro com três bolsistas de pesquisa. O critério de inclusão dos bolsistas nos grupos era ser bolsista de extensão ou pesquisa da IES estudada. Cada grupo teve duração de uma hora e meia. Na realização dos grupos focais utilizei as seguintes questões como norteadoras: O que é ser bolsista? Como vocês se sentem na IES? Percebem que o trabalho de vocês é importante? Qual o sentido dele para vocês? Quais as dificuldades/facilidades em ser bolsista? 
Um fator limitante do estudo foi o baixo número de participantes nos grupos, que acabou sendo menor do que o esperado. Enviei um convite via e-mail para todos os bolsistas de extensão e pesquisa participarem dos grupos. Possivelmente por ser um convite, e não convocação, muitos não vieram. De qualquer forma, não foram solicitados os motivos para a não participação dos demais bolsistas nos grupos. Apesar de saber que isso ocorre com frequência na técnica de grupos focais, esse foi um momento inicial de frustração para mim. Contudo, valorizei aqueles que estavam ali presentes. Como atividade inicial, de "quebra-gelo", solicitei que cada participante do grupo falasse o seu nome e/ou apelido, onde reside, qual o curso de frequenta, qual a área da bolsa que participa e alguma atividade de lazer.

No decorrer dos grupos, fui me surpreendendo. Os participantes falaram muito, talvez o número pequeno tenha favorecido essa atividade. Os grupos foram ricos de conteúdo e bem proveitosos. $\mathrm{O}$ tempo passou muito rápido. Enquanto mediadora, senti-me desafiada a fazer com que os participantes mantivessem o foco nas questões e a intervenção mostrou-me que sou capaz de estar ali, naquele papel. As questões foram esmiuçadas e o retorno dos participantes me motivou a levar o trabalho adiante.

Ao término da intervenção, outro desafio se anunciava - a transcrição de cada uma das entrevistas e dos grupos focais. Elas demandaram horas e horas de escuta e escrita. Contudo, valeram cada minuto, pois o resultado foi muito gratificante.

Para análise dos dados gerados nos grupos focais e entrevistas, foi utilizado o método de análise de conteúdo. A análise de conteúdo pode ser descrita como um conjunto de técnicas de análise de comunicações. É um único instrumento, porém caracterizado por uma grande disparidade de formas, adaptável ao campo da comunicação, que é extremamente vasto. Enfim, qualquer comunicação, ou seja, qualquer veículo de significados de um emissor a um receptor deveria poder ser escrito, decifrado, pelas técnicas da análise de conteúdo (BARDIN, 2011).

\section{RESULTADOS E DISCUSSÃO}

Serão apresentadas as categorias em subtítulos definidos a priori, ou seja, a partir da demanda da Instituição e das questões norteadoras. Após, trarei os dados obtidos nas entrevistas e grupos focais unidos pela articulação teórica. Nas falas, os " $E$ " serão os entrevistados e os " $G$ " serão os bolsistas participantes dos grupos focais. Alguns trechos das falas foram omitidos para não identificar a Instituição.

\section{Ser bolsista é aprender sempre}

Para os professores e bolsistas, ser um bolsista é buscar aprender sempre. É aprender além da sala de aula, articulando teoria e prática. É conhecer 
pessoas na realização das atividades diárias, participando de salões de iniciação científica e congressos. Assim podemos verificar nas seguintes falas:

Mais do que ganhar dinheiro é aprender. É justamente conhecer pessoas, aprender a pesquisar, 'se virar mesmo' sabe (G5).

O bolsista quer o conhecimento a mais do que aquele...ele tem em sala de aula o curso que ele escolheu pra ser sua futura profissão (G7).

Pode associar o estudo da graduação na prática e pode relacionar com tudo isso que a gente aprende, porque a gente vê muita coisa (G8).

Ser bolsista também é ser iniciante no processo de produção de conhecimento. É estar mais próximo do mundo científico, construindo possibilidades de ingressar na pós-graduação. Podemos conferir essas afirmações nas falas abaixo:

É uma oportunidade de aprendizagem, de toda, ou de pelo menos parte da dinâmica do que é fazer ciência (E4).

É um iniciado, você está iniciando um processo para a ciência, você está sendo iniciado para produzir conhecimento científico (E1).

Se bolsista tem um objetivo né, não é passa tempo e nem recebe valor, ele complementa a vida acadêmica do aluno, pode transformá-lo num futuro pesquisador (E2).

Atuar como bolsista é uma oportunidade de se vincular a diferentes áreas do conhecimento, encurtando, dessa maneira, o percurso até um mestrado ou doutorado, e construir uma carreira acadêmica, algo almejado por muitos bolsistas. As seguintes falas confirmam essa ideia:

Eu acho que atuar como bolsista é em primeiro lugar uma oportunidade que esse aluno tem em se vincular com diferentes áreas de conhecimento (E6).

O bolsista a gente pode dizer que ele é, a atividade de iniciação científica ela é um braço pra encurtar, pra facilitar a pós-graduação (E1).

Eu procurei a bolsa pra fazer mestrado (G1).

Além de facilitar o ingresso na pós-graduação, a bolsa foi descrita como uma oportunidade, apresentando uma dimensão muito maior, como podemos verificar nas falas:

Eu pensei em ser uma oportunidade, e aprendi mais do que eu esperava (G5). 
$\mathrm{Na}$ iniciação à pesquisa ou na própria extensão a gente percebe outra dimensão do conhecimento que é o papel da academia, da universidade em si, que é como se produz esse conhecimento, o que tu precisa pra produzi e também não só pro ensino mas como ele pode ir pra comunidade (G6).

Silva e Tolfo (2012, p.342) afirmam que o sujeito quer "tornar-se também por meio do trabalho o que de fato se deseja ser." A bolsa oferece aos sujeitos nela envolvidos um modo de ser, de pensar, de agir. A forma como os indivíduos trabalham e o que eles produzem reflete sobre o que pensam e na maneira como percebem sua liberdade e sua independência. $\mathrm{O}$ processo de trabalho, bem como seu fruto, auxilia o sujeito a descobrir e formar sua identidade (MORIN, 2001).

Os bolsistas são trabalhadores que possuem particularidades, mas da mesma forma como todos os outros trabalhos, em sua prática eles tem a oportunidade de crescer, envolver- se, engajar-se e construir-se profissionalmente, ou seja, o trabalho dedicado a bolsa atua como constituidor da identidade desses bolsistas.

\section{A relevância do trabalho dos bolsistas}

Todos os participantes do estudo acreditam que o bolsista tem papel fundamental na IES, sendo a base de todo o processo de produção de conhecimento, pois sem o trabalho deles os projetos não aconteceriam. Verificamos isso nos relatos abaixo:

O bolsista de iniciação científica ele é parte fundamental, ele é a base das pesquisas, ele é a base (E1).

A importância maior é que a ciência que a [...] faz, talvez não fosse possível sem a existência desses profissionais bolsistas (E4).

Extremamente importante porque os bolsistas auxiliam muito os coordenadores. Como eles têm horas específicas pra aquela atividade, eles auxiliam muito, então se não fossem os bolsistas muitos dos projetos não aconteceriam (E5).

O bolsista é essencial, precisa ter o bolsista pra pesquisa. Tem lá o professor que vai monta a pesquisa, vai lança a ideia né, mas quem efetua são os bolsistas (G7).

Além de serem a base para o desenvolvimento das pesquisas, os bolsistas foram descritos como aqueles que divulgam a IES para a comunidade:

Os bolsistas de extensão são pessoas fundamentais pra realização $e$ divulgação das atividades do projeto, na Instituição e fora também (E3). 
Tu vai estar levando o nome da Instituição nos salões de iniciação, nas revistas em que tu vai tá publicando (G2).

O trabalho dos bolsistas é importante para auxiliar a Instituição a se tornar Universidade. Como verificamos nas falas:

Se nós quisermos nos transformar em universidade nós precisamos de programas de pós-graduação. Para ter o programa de pós-graduação, nós precisamos ter mestres e doutores, mestrandos e doutorandos, para tê-los é preciso ter projeto de pesquisa, para ter projeto de pesquisa é preciso ter bolsista de iniciação científica. Então eles são a base para todo o processo (E1).

A [...] busca com as pesquisas hoje, aumenta, cresce, busca-se ser universidade. Então pra isso devem existir, tantos números $x$ de doutorado, número $x$ de mestrado, então as pesquisas levam a esses cursos e os bolsistas dentro da pesquisa desenvolvem isso, eles aumentam essas chances, né? (E2).

A universidade, ela se faz de várias maneiras, principalmente com a questão da pesquisa, hoje se a [...] quer se transforma em uma universidade, deixar de ser centro universitário, ela precisa investir no conhecimento e na comunidade. O bolsista tem que dá a base pra pesquisa (G6).

Assim como os entrevistados percebem que os bolsistas têm papel fundamental para a IES, foi importante perceber que eles também sentem a importância de seu trabalho para a mesma. De acordo com Mendes e Araujo (2012), o trabalho é visto, principalmente, como atividade social, em que existe a necessidade do outro. Ele é formado por várias dimensões, como a cultural e a social. Ou seja, trabalhar é viver junto. $\mathrm{O}$ trabalho é social por si só. As marcas de individuação que resultam dos modos de organização do trabalho hoje podem dirigir a um isolamento em vez de promover o espaço coletivo da fala, fundamental para a constituição do sujeito.

A relevância do trabalho para o sujeito é porque ele compõe um fenômeno psicossocial fundamental. Por meio de esforços físicos e psíquicos mediamos nossas relações com as pessoas. Logo, o trabalho se caracteriza como uma categoria central da vida humana (SILVA; TOLFO, 2012).

\section{Os desafios que envolvem os bolsistas}

As dificuldades encontradas para ser bolsista são variadas. Algumas são voltadas ao suporte oferecido pela IES, outras à falta de comprometimento de alguns bolsistas e de adequação à algumas normas institucionais. 
Eu acho que a principal dificuldade é a parte estrutural, a parte física mesmo, de eles poderem te um canto pra eles, uma mesa pra eles, deles poderem ficar mais próximos de mim, isso é uma coisa que eles reclamam muito (E1).

Dificuldade eu acho que é o que acontece em qualquer lugar, existem pessoas que são comprometidas e outras que não são né (E2).

A gente tem bolsistas que são muito mais empenhados, tem bolsista que abraça com alma e coração o seu trabalho, em vez de fazer suas vinte horas semanais ele faz quarenta horas semanais e ele acha aquilo maravilhoso e ele traz ideias pra gente e corre atrás, um espetáculo. Assim como tem aquele bolsista que às vezes não é tão empenhado, mas isso faz parte de todo o processo, porque, através da iniciação científica, a gente vai descobrir os novos talentos que a gente de repente vai ter pra pesquisa (E6).

Quanto às questões do cumprimento de algumas normas institucionais, foi mencionada a dificuldade de cursar inglês e cumprir os prazos, conforme as falas:

Dificuldade, o que é que acontece com os bolsistas. Aí às vezes, ele vai se inscrever pra um salão de extensão, só que tem prazos internos, tipo, não é fazer hoje e o boleto vence amanhã, o financeiro precisa de uma organização interna, então, esse cumprimento de prazos que eles acabam não fazendo, né? (E3).

Reserva de carro também, porque em muitos projetos de extensão eles vão, a maioria vai pra escola, vai pra comunidade. Então, lembrar que tem que ser feito com antecedência, que tem que pedir autorização, então, alguns sistemas internos assim, de gerenciamento, que até então não era a rotina dele, é isso também que a gente percebe (E3).

A realização obrigatória do inglês foi algo destacado pelos bolsistas. De modo geral os entrevistados e participantes dos grupos entendem que ele é um problema e não deveria ser obrigatório, deveria ser mais flexível, com possibilidade de cursar outras línguas. O Projeto i é um projeto destinado exclusivamente ao público interno, que tem vínculo com a instituição, ou seja, professores, funcionários, alunos e bolsistas da IES. É uma possibilidade de aprendizagem de inglês num formato diferenciado, utilizando como base o CEFR (Common European Framework of Reference for Languages). O incômodo da obrigatoriedade de cursar o inglês aparece nas seguintes falas:

A obrigatoriedade do inglês, isso causa problemas para a saúde do projeto, por exemplo, você é obrigado a fazer inglês, mas vocês têm que ir a campo ficar quinze dias, então essa obrigação, ela não deveria existir (E1).

Algumas coisas incomodam, que nem [...] tentar atingir metas [...], todo mundo pela questão da internacionalização, a gente precisa de inglês. É 
a gente precisa do inglês, mas, por exemplo, tem algumas linhas em que o italiano seria muito mais interessante na área da pesquisa, ou o francês seria muito mais interessante. Ás vezes a gente se sente um tanto obrigado ou desconfortável nesses quesitos (G6).

Além da relevância cultural e social que o trabalho possui, ele também reflete diretamente no sujeito. $O$ trabalho não é neutro para o sujeito, pois este se envolve com o corpo e o afeto, adentrando na relação com o trabalho individual e coletivo. É o sujeito que faz o trabalho vivo, diversas vezes mortificado pelas prescrições da organização do trabalho (MENDES; ARAUJO, 2012).

Segundo Morin (2001) é importante que a organização das tarefas e atividades torne-se favorável à eficiência e que os objetivos a serem atingidos sejam claros e significativos para as pessoas que o realizam. Penso que a relevância da obrigatoriedade do inglês para os bolsistas não esteja clara, refletindo-se na falta de engajamento por parte deles.

Também surgiu como dificuldade o fato de que a maioria dos estudantes da IES são trabalhadores, o que dificulta a seleção do grupo dos bolsistas:

Hoje a maior dificuldade que a gente tem é que boa parte dos nossos alunos são, antes de mais nada, trabalhadores, é um processo de selecionar esse grupo, né (E4).

Quando questionados sobre os desafios em ser bolsista, o grupo respondeu sobre a autonomia em realizar as atividades, apresentar sua pesquisa nas escolas e em salões de iniciação científica, bem como organizar seu tempo, conforme as falas a seguir revelam:

Essa questão da autonomia, de tu te dá conta disso, tu é responsável por tal ideia. (G2)

O maior desafio é se apresentar num salão de extensão. (G4)

Aprender a ser autônomo. Administrar teu tempo, teu conhecimento, acho que é muito isso, na iniciação científica tu aprender a ser autônomo. (G6)

Autonomia, e tu acaba descobrindo que tu é capaz de fazer aquilo, fazer apresentação, escrever, e isso é importante até pra tua autoestima. (G7)

De acordo com Diniz (2004) o trabalho é um local de construção de uma rede social de apoio e de validação da competência relacional. Ele constitui hoje fator importante de identidade e autoestima, uma vez que a capacidade produtiva e a produtividade passaram a ser determinantes cruciais de valor pessoal e social. Por isso, precisamos estar atentos ao significado que ele confere aos sujeitos. 
Porém, é preciso ter cuidado para que os salões de iniciação, a capacidade de organizar o tempo e as produções científicas não se tornem fatores estressores ocupacionais. A convivência com esses fatores, segundo Tamayo (2008), faz parte do cotidiano das atividades de trabalho, diferenciando-se de acordo com sua frequência e intensidade. $\mathrm{O}$ tipo de evento estressor, assim como suas formas de manifestação, muda conforme a situação e contexto ocupacional, bem como se modifica para cada pessoa.

O reflexo do caráter destrutivo do estresse tem provocado uma série de problemas para as organizações, entre elas estão o aumento do absenteísmo e da rotatividade, baixo rendimento e insatisfação. Esses são fatores que prejudicam a organização do processo de trabalho, a saúde dos trabalhadores e a produtividade (TAMAYO, 2008). Por isso é tão importante se atentar a eles.

\section{Fontes de realização e inspiração dos bolsistas}

A fonte de realização dos bolsistas da IES é o reconhecimento, tanto no grupo de amigos quanto pelos professores. Nos relatos abaixo podemos conferir:

É o reconhecimento. A gente tenta fazer o nosso melhor e qualquer reconhecimento é bom. (G2)

E até por parte dos amigos...eu acho isso super legal, poder passa conhecimento pros teus amigos. (G5)

A bolsa também é fonte de realização para aqueles que são questionadores. Ela é uma construção do futuro e favorece a autoconfiança, que beneficia o aluno e a comunidade:

Eu sou muito questionadora e a pesquisa é o lugar dos questionamentos. Isso pra mim é muito importante, que existe meu espaço, a pesquisa me realiza nesse sentido. (G6)

O que me deixa feliz é que eu tô construindo o currículo pra depois. E também querendo ou não algumas ideias do curso se cruzam. Tu começa a conhecer outras formas, professores, esse mundo acadêmico. (G3)

Tu te sentir capaz, querer buscar mais, acreditar em ti. (G7)

Os resultados que a gente tem no projeto são muito satisfatórios, a gente faz os testes e vê que tem muito potencial [...] ou até pode ajudar numa doença ou na cura do câncer e isso é muito legal. (G8)

De acordo com Zanelli, Silva e Soares (2010) o trabalho nos propicia interagir e ter suporte social, encontrar um objetivo ao qual valha a pena se dedicar, encontrar desafios, adquirir status e conseguir renda. Quando consideramos a relevância do trabalho na vida dos sujeitos, conforme Silva e 
Tolfo (2012) também consideramos as relações entre trabalho significativo e realização humana através de tarefas constituídas de importância para quem as realiza. A autorrealização implica encontrar propósitos válidos que oferecem sentido à existência humana nos planos de vida pessoal e no trabalho.

As fontes de inspiração dos bolsistas foram diversificadas. Dentre elas estão o assunto abordado no projeto, a construção da carreira, o grupo, os colegas e a proximidade entre os membros. As falas abaixo apresentam essa ideia:

Pra mim o assunto que me inspirou. (G1)

É o que eu realmente quero fazer, mestrado, doutorado, não quero parar de estudar. (G2)

O próprio grupo me inspira, as pessoas, o ambiente é muito bom, são ideias diferentes, é muito bom. (G4)

Acho que foram muito meus colegas que já eram bolsistas e eu percebia que a formação deles tava bem além da minha. (G6)

Entendo que a inspiração pode ser compreendida aqui como a motivação, é aquilo que move os bolsistas a procurarem esse contexto. De acordo com Tamayo e Pascoal (2003), a motivação laboral é orientada por uma abordagem positiva e humanizadora do ambiente de trabalho, buscando encontrar caminhos para auxiliar o sujeito a satisfazer suas necessidades no trabalho e se realizar profissionalmente nele.

\section{Aproximação com o grupo de bolsistas}

A aproximação, segundo os participantes da intervenção, divergiu entre eles. Para alguns a aproximação entre bolsistas, professores e os demais setores da IES é necessária, como podemos verificar nos relatos:

Eu acredito que sim, eu acho que a [...] deve fazer algo para aproximar. $O$ trabalho deles é importante, eles são importantes pra nós como Instituição, e até pra eles se sentirem bem, porque uma das reclamações, é que eles se sentiam afastados, como se não fossem alguma coisa aqui dentro, e não é bem assim, mas também é a posição como eles se colocam. (E2)

Há uma série de situações, de comportamentos, de valores que precisam ser desenvolvidos quesão inerentes a todoe qualquer bolsista independentemente do projeto ao qual ele participe. Então, há sim uma formação técnica pra ciência que é feita pelos pesquisadores, mas há um outro conjunto de habilidades, de competências que precisam ser desenvolvidos, que fazem parte sim da atribuição da Instituição. Então, aproximar-se, fazể-los sentirse parte do que é a Instituição como um todo, me parece fundamental. (E4)

Acho que sim, porque é mais uma forma deles viverem a Instituição. (E5) 
Eu acho que a aproximação é natural e essa aproximação tem que ser intensa entre orientador e o bolsista, é o que vale. (E1)

Também foi dado um retorno positivo quanto ao que já foi feito para integrar este grupo à IES. Isso confirmamos na falas a seguir:

Eles (bolsistas) têm um curso de inglês que eles podem fazer, então assim, isso é muito bom, então a Instituição ela está fazendo o seu papel. (E1)

Eu acho que todas essas ações que a gente tá fazendo desde o ano passado junto com o $R H$, eu acho que isso já aproximo muito né. (E3)

Nessa relação entre os bolsistas e a IES é relevante destacar que o processo de trabalho possibilita a formação da identidade do sujeito, segundo Mendes e Araujo (2012), em que o olhar para o mesmo é de um ser ativo, protagonista desse contexto. Esse papel ativo do sujeito rompe a visão maniqueísta de organização perversa e trabalhador passivo e submisso. $O$ trabalhador deseja se engajar, pensar e fazer. E, buscando se aproximar desse grupo, acredito que a IES esteja atenta aos bolsistas, considerando eles como seres ativos nesse contexto.

Quando questionados sobre como os bolsistas se sentiam na IES, os mesmos disseram que gostam muito de estar na Instituição, porém algumas normas institucionais incomodam como o inglês obrigatório e o cumprimento dos prazos. Segundo Mendes e Araujo (2012) é preciso ter cuidado com o excesso de padrões exigidos nas organizações que minam o potencial do sujeito, não permitindo a liberdade para o exercício do ser, para transformar o trabalho e se constituir a partir dele, para ter sua marca pessoal no que faz, sendo bloqueada essa relação dialética entre trabalho e sujeito-trabalhador. Entendo que é preciso possibilitar aos bolsistas essa liberdade do ser. Como pesquisadores, autores das práticas de pesquisa, pois os padrões rígidos podem resultar em muitas perdas importantes para trabalhador e instituição. As falas abaixo deixam evidente essa afirmação:

Nossa, eu tenho muito orgulho da [...]. (G5)

Eles tentam nos valorizar de alguma maneira, tentam trazer a gente pros grupos de reuniões de funcionários, entre outras coisas, de alguma maneira eles tentam trazer direitos que a gente não tem, se a gente for vê pela legislação a gente não é considerado trabalhista, então de alguma maneira eles tentam disponibilizar espaços melhores pra gente. Mas algumas coisas incomodam. A pesquisa em si te dá uma autonomia muito grande pra tu administra, mas daí entra uma ou outra coisinha institucional que às vezes te barra. (G6) 
trabalhar é

Assim como as respostas dos bolsistas foram subjetivas e singulares, a mobilização subjetiva frente ao real do trabalho, que envolve a atividade laborativa concreta, pois é partir da organização do trabalho prescrita e efetiva que se potencializa a atividade psíquica, representada na elaboração e perlaboração. A elaboração implica pensar as relações entre as ideias, apropriar-se dos afetos, tornar inteligível o desconhecido - como ocorre na interpretação dos sonhos -, processar, absorver e atribuir sentido ao mundo. Esse sentido é perpassado pelas vivências de prazer e sofrimento (MENDES; ARAUJO, 2012, p. 26).

Assim, o trabalho pode ser divido em dois: o prescrito e o real. $\mathrm{O}$ trabalho prescrito é aquele que consta nas normas, manuais e no modo como deve ser desenvolvido. Já o trabalho real é aquele que é de fato realizado, englobando a prática e o cotidiano (MERLO; BOTTEGA; PEREZ, 2014). Ao me aproximar desse grupo, acredito que a IES esteja atenta aos bolsistas, considerando eles como seres ativos nesse contexto.

\section{Sugestões no trabalho com os bolsistas}

Os participantes do estudo sugeriram melhorias para o trabalho dos bolsistas, voltadas à infraestrutura oferecida pela IES, à alimentação e maior flexibilidade na realização do curso de inglês. Também foi sugerido um espaço de encontro para os bolsistas, conforme as falas abaixo:

Dentro dos setores, eu acho que eles têm que ter essa, essa... estrutura de ter uma mesa pra eles, de poderem colocar a mochila deles, um armário, eu acho que isso é fundamental. E a outra situação é dar um pouco mais de flexibilidade a essas, essa coisa do inglês, essas obrigatoriedades, eles terem que fazer curso coisa e tal, apesar que não é obrigatório aqueles cursos de aperfeiçoamento, não é obrigatório. (E1)

As salas, o espaço é um problema. Tá faltando sala e a gente vai perder nossa sala, então sei lá, a cada prédio poderia ter uma sala pros bolsistas. (G2)

Eu acho que ter mais alguém pra auxilia, porque eles precisam de mais atenção, e ahm, esses cursos de aperfeiçoamento acho que são muito bons. Aproxima eles até pra eles vê que a gente tá jogando do mesmo lado. (E2)

Se quiserem ajuda na alimentação. (G1)

Coisas muito pequenas, tipo grampeador, coisas básicas que a [...] poderia disponibilizar. (G6) 
Deveria ter algum tipo de, não evento, uma reunião uma vez por semana, pra se reunir e faze uma conversa como aqui. (G5)

Não tem um espaço de reuniões específico para a pesquisa, isso é questão de se organizar. (G6)

Tratando-se de melhorias no contexto laboral, segundo Tamayo e Paschoal (2003), considerando a complexidade do trabalho nas organizações, as diversas demandas, os ambientes mais competitivos e almejando a produção, as organizações têm como corolário a necessidade de valorizar os funcionários e de proporcionar condições que potencializem o desempenho e a satisfação na realização do trabalho dos mesmos.

Por outro lado, cabe ressaltar a presença de avaliações positivas e opiniões reflexivas sobre as condições ofertadas pela IES aos bolsistas, como podemos conferir nas falas:

Eu não queria me comprometer agora a propor alguma sugestão sem ter feito uma avaliação daquilo que se está fazendo hoje, pra dizer se isso é suficiente ou não né. (E4)

Eu acho que não. Em primeiro lugar eu acho que o trabalho que a Instituição faz aqui com os alunos né, graduação, iniciação científica, o que oferece pros professores... é, eu tô há dois anos aqui na instituição, mas é, eu sinto aqui a instituição assim, nossa, um trabalho muito bom, muito bem apresentada, um enfoque muito bom, a busca, a luta por trás das melhorias e como a gente vê como cresce, muito bom. (E6)

Hoje assim ó, realmente com relação ao funcionamento do projeto, aos professores que aderiram a causa, aos alunos que participam a gente não tem dificuldades, então tá cada vez melhor, tá cada vez melhor, sinceramente, tá cada vez melhor, a gente se orgulha muito de dizer isso. (E5)

Não é a instituição que tem que ir atrás e chama, gente, tem um cursinho aqui, vamo faze, eu acho que cada um tem que da um tem que corre atrás. (E6)

Na finalização dos grupos focais sugeri que cada um expressasse uma palavra que representasse o momento e esclarecesse porque lembrou dessa palavra. Esse momento foi muito bom não só para eles, mas para mim também. Enquanto estagiária, percebi que a minha atuação junto aos grupos foi muito significativa, pois além de promover um espaço de reflexão, a oportunidade de falar motivou-os a desacomodar-se e impulsionar outros movimentos. As palavras foram as seguintes: 
Expressão, porque ninguém nunca perguntou nossa opinião pra nada, né. Talvez isso não vai gerar nenhuma mudança, mas ninguém nunca nos perguntou o que tu acha, tu tá feliz, essa é minha palavra. (G1)

Compartilhar, compartilhar as mesmas coisas, as mesmas dificuldades. (G2)

Política, porque politica a gente faz no dia-a-dia, a gente vive isso e se uniu aqui pra pensar sobre isso, e isso é importante em qualquer lugar. (G3)

Opinião, é bom a gente se reunir. (G4)

Aproximação, porque as bolsistas que eu conheço são as que trabalham na minha sala, e as gurias aqui eu nem sabia que eram bolsistas. (G5)

Espaço, é um espaço que o bolsista poder vir e expressar coisas. (G6)

Conquista, eu acho que o fato de alguém estar nos ouvindo já é uma conquista. Alguém pensou: Vamos ouvir os bolsistas, o que eles pensam, como se sentem. Então eu acho que a palavra conquista cabe bem. (G7)

Ideia, acho que é um lugar em que a gente troca ideias, eu não conhecia como eram os outros projetos e foi uma maneira de os conhecer. (G8)

Na realização dos grupos acredito ter promovido, mesmo que de modo incipiente, o que, segundo Mendes e Araujo (2012), é a clínica do trabalho, que tem como objetivo criar um espaço de fala para o sujeito e, ao mesmo tempo, intervir no discurso, dando condições de ressignificar as vivências do trabalho. Minha intervenção não foi psicoterapêutica, mas ao realizar os questionamentos abri espaços aos participantes para falar e refletir sobre a experiência de ser bolsista. Além disso, foi uma oportunidade para dar novos sentidos a atuação deles e proporcionar um momento de trocas e de identificações.

Segundo as autoras acima citadas, criar espaços para a fala e discussão tornam-se potencialmente positivos para surgir um modo de gestão efetivo, com a participação de todos, e um sentimento de pertencimento que permite aos trabalhadores continuarem se engajando. Os bolsistas tiveram nesse momento de grupo um espaço de fala e discussão sobre ser bolsista da IES, o qual oportunizou a possibilidade de participação de todos.

\section{CONSIDERAÇÕES FINAIS}

Cheguei à conclusão de que não existe um jeito único de ser bolsista. Os modos de perceber e ser bolsista estão relacionados à produção do conhecimento e as atividades dela decorrentes, como integrar grupos de pesquisa, participar de eventos científicos e auxiliar na construção da carreira 
acadêmica. Os desafios que esse grupo enfrenta são os mais variados, mas a realização pessoal e os benefícios também o são.

Por meio da intervenção foi possível promover um espaço para pensar sobre os processos de trabalho e problematizá-los, de modo que possam ser criados novos caminhos para a realização do trabalho com os bolsistas. Um desses caminhos foi oportunizado por meio deste estudo, o de promover um encontro para que os bolsistas pudessem integrar-se, trocar ideias e experiências.

Sugere-se a manutenção dos encontros mensais entre os bolsistas, com livre escolha do tema a ser abordado. Um espaço que atue como oportunidade de integração e de aproximação uns com os outros, com seus professores e coordenações dos grupos de pesquisa e de extensão. Pude perceber, em minha intervenção, que eles valorizaram muito esse espaço de fala, que foge aos espaços tradicionais oferecidos para troca de produções acadêmicas e científicas.

Quanto à maior destinação de tempo dos professores aos bolsistas poderiam ser organizados encontros fixos, semanais, para essa atividade, pois acredito que uma maior vinculação entre professor e bolsista promoverá um sentimento maior de pertencimento no bolsista. Com os bolsistas sendo mais envolvidos pelos professores, teremos bolsistas mais comprometidos com a pesquisa, extensão e com a IES.

Da mesma forma, acredito ser necessário realizar encontros entre os coordenadores dos projetos e os bolsistas com um representante do $\mathrm{RH}$ para manter todos informados sobre os deveres e direitos dos bolsistas e as diferenças existentes nos benefícios dirigidos a esses e aos funcionários da IES.

Também notei o quanto a obrigatoriedade em realizar o Projeto $i$ é um desencontro para os bolsistas. Talvez fosse necessário permitir a estudo de outras línguas, além, do inglês, pois, em algumas áreas, como foi relatado, essa não é a melhor opção. Ou ainda promover um encontro com os bolsistas para apresentar a importância da língua inglesa no contexto mundial para a produção do conhecimento. Os encontros são uma estratégia que aproxima as pessoas, permitem que as mesmas entendam esse universo particular e construam em conjunto novos caminhos.

Os bolsistas integram um grupo crítico, muito bom para a construção da futura profissão, porém, em relação às normas, percebi que quanto mais instituídas e verticalizadas, mais difíceis de serem aceitas elas são. Se forem pensadas juntas, horizontalmente, acredito que serão mais efetivas, farão mais sentido.

De modo geral, percebo que na IES existem práticas instituídas, que constantemente são questionam pelos pessoas que ali circulam, os quais buscam melhorar as suas práticas, fazendo surgir o instituinte. Segundo Baremblitt (2002), o instituinte representa os momentos de transformação, produção, criação e o instituído é aquilo que é resultado dessa produção, é efeito da 
atividade instituinte. $\mathrm{O}$ instituinte aparece como um processo, enquanto o instituído aparece como um resultado. $\mathrm{O}$ instituinte é dinâmico; o instituído é estático.

Finalizo minhas considerações percebendo que estou no caminho, como afirma Passos (2007), no qual o psicólogo, nas organizações, precisa ter uma postura questionadora, reflexiva e articulada. Sinto que meus objetivos com o estágio curricular, considerando especialmente a intervenção, foram alcançados. Além disso, meus conhecimentos foram ampliados e minha autonomia como profissional da psicologia foi fortalecida.

\section{REFERÊNCIAS}

BARDIN, Laurence. Análise de conteúdo. São Paulo: Edições 70, 2011.

BAREMBLITT, Gregorio F. Sociedades e instituições. In: Compêndido de Análise Institucional e outras correntes: teoria e prática. 5 ed. Belo Horizonte, MG: Instituto Félix Guatarri, 2002. p. 25-36.

DINIZ, Gláucia. Mulher, trabalho e saúde mental. In. CODO, Wanderley. O trabalho enlouquece? Um encontro entre a clínica e o trabalho. Petrópolis, RJ: Vozes, 2004. p. 105-138.

FLICK, Uwe. Introdução à coleção pesquisa qualitativa. In: BANKS, Marcus. Dados visuais para pesquisa qualitativa. Porto Alegre: Artmed, 2009. p. 7-11.

FRASER, Márcia T. D.; GONDIM, Sônia M. G. Da fala do outro ao texto negociado: discussões sobre a entrevista na pesquisa qualitativa. Universidade Federal da Bahia, Paidéia, 2004.

GATTI, Bernardete Angelina. Grupo focal na pesquisa em Ciências Sociais e Humanas. Brasília: Líber Livro Editora, 2005.

GIL, Antonio C. Métodos e técnicas de pesquisa social. 6 ed. 4 reimp. São Paulo: Atlas, 2011.

GUEDES, João. Muito além da cota. Revista Proteção. Março, 2013.

GUIRADO, Marlene. Psicologia Institucional. 2 ed. Rev. e amp. São Paulo: EPU, 2004.

GOLDENBERG, Mirian. A arte de pesquisar: como fazer pesquisa qualitativa em Ciências Sociais. 13ª ed. Rio de Janeiro: Record, 2013.

MENDES, Ana M.; ARAUJO, Luciane K. R. Condições institucionais, políticas e éticas para prática clínica. In: Clínica Psicodinâmica do Trabalho: o sujeito em ação. Curitiba: Juruá, 2012. p. 129-135. 
MERLO, Álvaro R. C.; BOTTEGA, Carla G.; PEREZ, Karine Vanessa. Atenção ao sofrimento e ao adoecimento psíquico do trabalhador e da trabalhadora: cartilha para profissionais do Sistema Único de Saúde - SUS. Porto Alegre: Evangraf, 2014.

MORIN, Estelle M. Os sentidos do trabalho. Revista de Administração de Empresas. São Paulo, v. 41, n. 3, Jul./ Set. 2001. p. 8-19.

OSORIO, Luiz C. Práxis Grupal. In: Psicologia Grupal: uma nova disciplina para o advento de uma era. Porto Alegre: Artmed, 2003. p. 115-161.

PINHEIRO, Odette de G. Entrevista: uma prática discursiva. In: SPINK, Mary Jane P. Práticas discursivas e produção de sentido no cotidiano: aproximações teóricas e metodológicas. 3 ed. São Paulo: Cortez, 2004. p. 183-214.

SILVA, Narbal; TOLFO, Suzana R. Trabalho significativo e felicidade humana: explorando aproximações. Revista de Psicologia: Organizações e Trabalho. 2012. p. 341-354.

TAMAYO, Álvaro. Estresse e Cultura Organizacional. São Paulo: Casa do Piscólogo: All Books, 2008.

TAMAYO, Álvaro; PASCHOAL, Tatiane. A relação da motivação para o trabalho com as metas do trabalhador. RAC, v. 7, n. 4, Out./ Dez. 2003: 33-54.

ZANELLI, J. C; SILVA, N.; SOARES D. P. Orientação para aposentadoria nas organizações de trabalho: construção de projetos para o pós-carreira. Porto Alegre: Artmed, 2010. 